\title{
Optimal coordinated bidding of a profit-maximizing heat pump aggregator: The Dutch case
}

Vardanyan, Yelena; Wolf, Armin; Bacher, Peder; Valalaki, Katerina; Leerbeck, Kenneth; Tual, Roland; Cuno, Silke

\section{Published in:}

Proceedings of 2020 International Conference on Smart Grids and Energy Systems

Link to article, DOI:

10.1109/SGES51519.2020.00020

Publication date:

2021

Document Version

Peer reviewed version

Link back to DTU Orbit

Citation (APA):

Vardanyan, Y., Wolf, A., Bacher, P., Valalaki, K., Leerbeck, K., Tual, R., \& Cuno, S. (2021). Optimal coordinated bidding of a profit-maximizing heat pump aggregator: The Dutch case. In Proceedings of 2020 International Conference on Smart Grids and Energy Systems (pp. 71-76). IEEE.

https://doi.org/10.1109/SGES51519.2020.00020

\section{General rights}

Copyright and moral rights for the publications made accessible in the public portal are retained by the authors and/or other copyright owners and it is a condition of accessing publications that users recognise and abide by the legal requirements associated with these rights.

- Users may download and print one copy of any publication from the public portal for the purpose of private study or research.

- You may not further distribute the material or use it for any profit-making activity or commercial gain

- You may freely distribute the URL identifying the publication in the public portal 


\section{Optimal coordinated bidding of a profit-maximizing heat pump aggregator: The Dutch case

\author{
Yelena Vardanyan \\ DTU Compute
} Technical University of Denmark \\ Kng. Lyngby, Denmark \\ yeva@dtu.dk

\author{
Armin Wolf \\ IT4Energy Center \\ Fraunhofer Institute \\ Berlin, Germany \\ armin.wolf@fokus.fraunhofer.de
} \\ Peder Bacher \\ DTU Compute \\ Technical University of Denmark \\ Kng. Lyngby, Denmark \\ pbac@dtu.dk, \\ Kenneth Leerbeck \\ DTU Compute \\ Technical University of Denmark \\ Kng. Lyngby, Denmark \\ kenle@dtu.dk \\ Katerina Valalaki \\ HYPERTECH S.A. \\ Athens, Greece \\ k.valalaki@hypertech.gr \\ Roland Tual \\ REScoop.eu \\ Brussels, Belgium \\ roland.tual@rescoop.eu}

Silke Cuno

IT4Energy Center

Fraunhofer Institute

Berlin, Germany

silke.cuno@fokus.fraunhofer.de 


\begin{abstract}
An aggregator is a business entity enabling smooth cooperation between a System Operator (SO) and small customers to trade electric power. In this cooperation each market actor (aggregator, small customer, system operator) looks for its own economic incentives. In this paper, we consider an aggregator, who manages a portfolio of domestic heat pumps (HPs). The aggregator aims at maximizing its profit while trading energy and providing balancing power in wholesale markets. The paper develops a Mixed Integer Linear Program (MILP) for optimal coordinated bidding of HPs consumption power in competitive day-ahead and real-time markets. The model enables an aggregator to shift the consumption of HPs to hours with lower market prices, while respecting the comfort of involved houses. A case has been studied based on data from Dutch pilot built in the scope of FLEXCoop project. Day-ahead and balancing market prices have been obtained from TenneT.
\end{abstract}




\section{Nomenclature}

\section{$1.1 \quad$ Indices}

$\mathrm{k} \quad$ index for heat pumps, $k=1, \ldots, K$;

$\mathrm{t}$ planning periods, $t=1, \ldots, T$;

\subsection{Parameters}

$\Delta t \quad$ Time duration of each time steps [h];

$\bar{P}_{k} \quad$ The maximum electric power of the $k^{t h}$ heat pump $[\mathrm{kW}]$;

$\underline{T}_{k, t} / \bar{T}_{k, t} \quad$ Min./max. allowable room temperature of the $k^{t h}$ house at time step $t\left[{ }^{\circ} \mathrm{C}\right]$;

$T_{k, t=0} / T_{k, t}^{\text {ref }} \quad$ Starting/reference temperature level for the $k^{\text {th }}$ house $\left[{ }^{\circ} \mathrm{C}\right]$;

$T_{k, t}^{\text {out }} \quad$ Outdoor temp. affecting the $k^{\text {th }}$ house $\left[{ }^{\circ} \mathrm{C}\right]$;

$\gamma_{t} \quad$ Weight factor between cost and discomfort; $R_{k} \quad$ Thermal resistance of $k^{\text {th }}$ house $\left[{ }^{\circ} \mathrm{C} / \mathrm{kW}\right]$;

$C_{k} \quad$ Heat capacity of $k^{t h}$ house $\left[\mathrm{kWh} /{ }^{\circ} \mathrm{C}\right]$;

$f_{k, t}^{\text {cop }}\left(T_{k, t}^{\text {out }}\right) \quad$ The $k^{t h}$ heat pump COP as a function of the outdoor temperature at time step $t$;

$D_{k, t} \quad$ Daily load pattern of the $k^{\text {th }}$ house within time period $t[\mathrm{~kW}]$;

$\Delta P_{k} \quad$ The maximum electric power gradient of the $k^{\text {th }}$ heat pump $[\mathrm{kW} / \mathrm{h}]$;

$\boldsymbol{\Phi}_{k}(\Delta t) \quad$ Discrete time auto regressive (AR) model part for heat dynamics of the $k^{t h}$ house;

$\boldsymbol{\Gamma}_{k}(\Delta t) \quad$ Discrete time exogenous model part for heat dynamics of the $k^{t h}$ house;

$\lambda_{t} \quad$ Day-ahead market prices for period $t$ $[€ / \mathrm{MWh}]$

$\lambda_{t}^{\mathrm{up} / \mathrm{dn}} \quad$ Real-time market prices for up-/downregulation within time period $t[€ / \mathrm{MWh}]$;

$c_{t} \quad$ Aggregator's offers to HP owners for dayahead trading [€/MWh];

$c_{t}^{u p / d n} \quad$ Aggregator's offers to HP owners for realtime trading [€/MWh]; 


\subsection{Variables}

\begin{tabular}{|c|c|}
\hline$p_{k, t}$ & $\begin{array}{l}\text { Day-ahead dispatch level for } k^{t h} \text { heat pump } \\
\text { at time step } t[\mathrm{~kW}]\end{array}$ \\
\hline$p_{k, t}^{\mathrm{up} / \mathrm{dn}}$ & $\begin{array}{l}\text { Real-time up/down-regulation level for } k^{t h} \\
\text { heat pump at time step } t[\mathrm{~kW}]\end{array}$ \\
\hline$A P_{t}$ & $\begin{array}{l}\text { Aggregated day-ahead offer at time step } t \\
{[\mathrm{MW}] ;}\end{array}$ \\
\hline$A P_{t}^{\mathrm{up} / \mathrm{dn}}$ & $\begin{array}{l}\text { Aggregated up/down-regulation volume at } \\
\text { time step } t[\mathrm{MW}]\end{array}$ \\
\hline$T_{k, t}$ & $\begin{array}{l}\text { Indoor room temperature in } k^{t h} \text { house at } \\
\text { time step } t\left[C^{o}\right]\end{array}$ \\
\hline$B_{k, t}$ & $\begin{array}{l}\text { "Baseline" temperature in } k^{t h} \text { house at } \\
\text { time step } t\left[C^{o}\right] ;\end{array}$ \\
\hline$\delta_{k, t}$ & $\begin{array}{l}\text { Discriminator for up/down-regulation in } \\
\text { real-time market per site } k \text { at time step } t \\
{[0 / 1] \text {; }}\end{array}$ \\
\hline
\end{tabular}

\section{Introduction}

The European Union (EU) is committed to reducing greenhouse gas emissions significantly by 2050 [1]. To accomplish this goal, the share of renewable energy sources (RES) has to increase significantly. Challenges related to keeping a high security of supply have raised while the share of intermittent RES is increasing. Distributed energy resource (DER) units, located at distribution level such as automic loads (AL), electric vehicles (EVs), thermostatically controlled loads (TCLs), heat pumps (HPs) bring forth an additional opportunity for flexible power. The possible gain from the DER integration on the whole system is investigated in detail in [2] and [3].

Single DER cannot enter to an electricity market to trade their energy for two reasons: 1) the available flexibility potential of a DER is below the threshold to participate in ancillary service markets and 2) the participation of a DER will increase the number of market actors. Hence, market entities such as aggregators are required to enable smooth cooperation between DER owners and SO. The aggregator/retailer, through the development of novel demand response (DR) tools, makes it possible for small DERs to participate in these flexible markets and obtain additional revenues.

The ancillary service market in the Netherlands allows flexibility provision from both generation and demand side. Therefore, the aggregator aims at addressing ancillary service provision by aggregating DER units and entering the automatic Frequency Restoration Reserve (aFRR) market. It focuses on investigating flexibility potential - mainly from HPs. Thus, the aggregator needs to accurately estimate the flexibility of its entire portfolio and bid to the aFRR market respecting the existing market rules and regulations.

The main target of the HP aggregator, as a market entity, is to buy the 


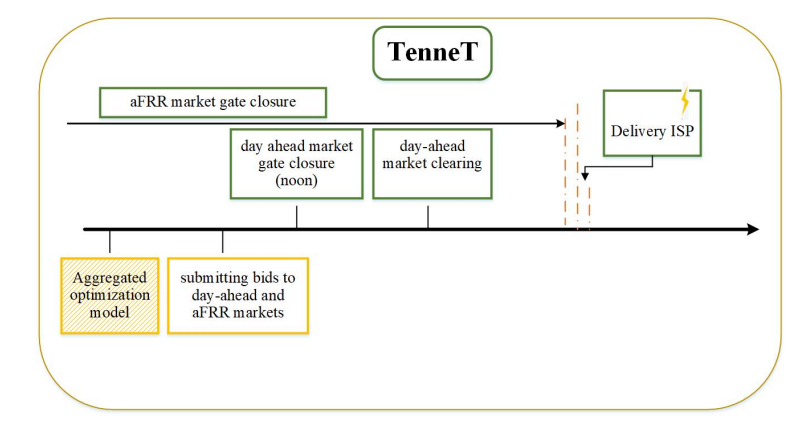

Figure 1: Timeline for physical trading and optimization procedure.

electric power at the lowest possible cost to satisfy the consumption needs of the HPs [4], [5] and [6]. Meanwhile, the economic incentive of the aggregator is to increase its revenue by performing energy arbitrage. Reference [4] presents a method that takes advantage of heat capacity in single-family houses using HPs to address large market price fluctuations caused by wind power over- or underproduction. While the authors in [5] consider a portfolio of domestic HPs controlled by an aggregator to participate in day-ahead and regulating markets. The reference [5] models the HP aggregator's participation in day-ahead and balancing markets sequentially. Sequential bidding may not enable the aggregator to allocate the electric power optimally and grasp every opportunity in the balancing market. Authors in [6] also address the potential of ancillary service provision from an aggregated portfolio of residential HP units. The paper [6] presents a quantitative method to simulate the bidding process while taking historical frequency and HP input data.

Unlike the previous references, this paper develops coordinated optimal bidding MILP model for an HP aggregator to derive optimal bids for day-ahead and balancing markets. Main contribution of this paper is the development of a full optimization framework enabling HP aggregator to derive optimal bids for day-ahead market and to provide ancillary service while participating in aFRR market. The optimal bidding model is built addressing Dutch market rules. In addition, analyses are carried out based on data from the Dutch pilot accomplished in the scope of FLEXCoop project and historical day-ahead and aFRR market prices from Dutch Transition System Operator's (TSO) website (TenneT). Finally, the discussion of the results are provided simulating the original 'benchmark' and 'modified' optimization models. The 'modified' version is created to make the model more realistic and better account for the real life situations.

Fig.1 depicts the time line for physical electric power trading in day-ahead and balancing markets, as well as the optimization framework enabling HP aggregator to derive optimal bids. The gate closure and market clearing times are based on the Dutch power system case.

The paper is structured as follows. Section III introduces the general decision making procedure of a HP aggregator participating in day-ahead and aFRR 
markets, expresses the aggregated optimal bidding model as MILP. Section IV provides the case-study results, Section V concludes the paper and a method to calculate heat pump parameters is provided in Section VII.

\section{Problem Statement and Methodology}

\subsection{Market places}

As a convention, the Dutch electricity market can be split into the wholesale market on one hand which includes all the interactions between market participants (generators, traders, retailers, etc.), and the balancing market which is centrally run by the Dutch TSO, Tennet, in the Netherlands, as the ultimate responsibility for the balancing of the grid. Within the wholesale market, short-term markets include the day-ahead market and the intra-day market, both traded on the power exchange EPEX. The intra-day market is out of the scope of this paper, hence, the description of the intra-day market is omitted for brevity.

Day-ahead market description and requirements The bidding process in the day-ahead market operated by EPEX needs to comply with the following rules:

- The market is open 365 days a year; day-ahead market auction takes place once per day.

- The market opens 45 days in advance and closes on the day before delivery at noon.

- Bids with hourly resolution can be submitted for all hours of the next day before the closure of day-ahead market.

- After the closure of day-ahead market, the TenneT runs an economic dispatch problem. The market clearing results are published from 12:50.

Balancing market description and requirements The balancing market is structured in a set of products enabling TenneT to face any type of deviations from the smallest to the most significant. Regulating Power Reserves or automatic Frequency Regulation reserves (aFRR,) according to European denominations, is one such standard service procured by TenneT. This product can be offered as a contracted product, with the obligation to bid or on a voluntary basis [7], [8] and [9]. In the current paper, we assume the HP aggregator derives voluntary bids to participate in the mentioned above markets. The bidding process in the aFRR market has to respect the listed rules:

- Contrarily to contracted bids, the free bids with 15 minutes duration are traded continuously.

- Minimum bid size to enter aFRR market is $1 \mathrm{MW}$. 
- The bids are nominated per imbalance settlement period (ISP), based on the bid ladder where all suppliers are ranked by price.

- The delivered aFRR energy will be remunerated at pay-as-clear scheme.

\subsection{Decision process framework}

A brief description for the involved players (a HP aggregator and end users) with their objectives is provided to interpret the decision making process.

\subsubsection{Aggregators}

The typical decision-making procedure of an aggregator is similar to the decisionmaking mechanism of a usual retailer/customer. Particularly, the decisionmaking process of an HP aggregator is two-fold; on one hand, the heat pump aggregator strives against other market players for the lowest possible consumption cost in the day-ahead market and profit-optimal ancillary service provision in the real-time market. On the other hand, the HP aggregator competes with rival aggregators or retailers to attract more end users by offering better price incentives.

In fact, the main economic incentive of the aggregator is the maximization of its operating profit. Thus, such market player discovers its optimal power allocation in coordinated day-ahead and balancing markets, meanwhile determining competitive price incentives for the end users. The aggregator's cost directly depends on the cleared market prices and HP consumption allocation. However, its revenue is calculated considering the offered retail prices. Obviously, the prices in day-ahead and balancing markets are uncertain and are estimated exogenously. Therefore, it is reasonable to assume that the HP aggregator does not have market power in those mentioned above market floors. Thus, the HP aggregator in this work is considered as a price-taker.

\subsubsection{End Users}

The heat pump owners aim at achieving the least possible cost of their consumption while heating/cooling houses. Therefore, HP owners are motivated to shift their consumption to relatively lower price periods according to their comfort zones, as well as to purchase the energy quantity they need from the most price attractive aggregator.

\subsection{Proposed Mathematical problem formulation}

The optimization model MILP follows:

$$
\begin{aligned}
\max _{\Psi} \sum_{t, k}[ & \left(\lambda_{t}^{\mathrm{up}}-c_{t}^{u p}\right) p_{k, t}^{\mathrm{up}} \Delta t-\left(\lambda_{t}^{\mathrm{dn}}-c_{t}^{d n}\right) p_{k, t}^{\mathrm{dn}} \Delta t \\
& \left.-\left(\lambda_{t}-c_{t}\right) p_{k, t} \Delta t-\gamma_{t}\left|T_{k, t}^{\mathrm{ref}}-T_{k, t}\right|\right]
\end{aligned}
$$


subject to

$$
\begin{aligned}
& T_{k, t}=\boldsymbol{\Phi}_{k}(\Delta t) T_{k, t-1} \\
& +\boldsymbol{\Gamma}_{k}(\Delta t)\left[\begin{array}{c}
T_{k}^{\text {out }} \\
f_{k, t}^{\mathrm{cop}}\left(T_{k}^{\mathrm{out}}\right)\left(p_{k, t}+p_{k, t}^{\mathrm{dn}}-p_{k, t}^{\mathrm{up}}+D_{k, t}\right)
\end{array}\right] \\
& 0 \leq p_{k, t}+p_{k, t}^{\mathrm{dn}}-p_{k, t}^{\mathrm{up}} \leq \bar{P}_{k} \\
& p_{k, t}^{\mathrm{dn}} \leq \delta_{k, t} \bar{P}_{k} \\
& p_{k, t}^{\mathrm{up}} \leq\left(1-\delta_{k, t}\right) \bar{P}_{k} \\
& \left|\left(p_{k, t}+p_{k, t}^{\mathrm{dn}}-p_{k, t}^{\mathrm{up}}\right)-\left(p_{k, t-1}+p_{k, t-1}^{\mathrm{dn}}-p_{k, t-1}^{\mathrm{up}}\right)\right| \\
& \leq \Delta P_{k} \\
& \underline{T}_{k, t} \leq T_{k, t} \leq \bar{T}_{k, t} \\
& \sum_{k} p_{k, t}=A P_{t} \\
& \sum_{t} p_{k, t}^{\mathrm{up}}=A P_{t}^{\mathrm{up}} \\
& \sum_{t} p_{k, t}^{\mathrm{dn}}=A P_{t}^{\mathrm{dn}} \\
& p_{k, t}, p_{k, t}^{\mathrm{dn}}, p_{k, t}^{\mathrm{up}}, A P_{t}, A P_{t}^{\mathrm{up}}, A P_{s}^{\mathrm{dn}} \text { and } T_{k, t} \geq 0 .
\end{aligned}
$$

where $\Psi=\left\{p_{k, t}, p_{k, t}^{\mathrm{dn}}, p_{k, t}^{\mathrm{up}}, T_{k, t}\right\}$ is the set of decision variables of the MILP in (1)-(11). The aggregator aims at maximization of its profit from trading the electric power in day-ahead and real-time markets, which is expressed in (1). To participate in the day-ahead or down-regulating markets the aggregator needs to buy electric power from the SO with the estimated market prices and sell it to the end users with the agreed prices (settled in the contract). In contrast, to provide up-regulating bids, the aggregator needs to sell electric power to the SO with the estimated prices while buying it from the customers with the agreed prices.

The model of the heat dynamics of house $k$ is the first order differential equation as

$$
\begin{aligned}
\frac{d T_{k}}{d t} & =\frac{1}{R_{k} C_{k}}\left(T_{k}^{\text {out }}-T_{k}\right)+\frac{1}{C_{k}}\left(f _ { k , t } ^ { \text { cop } } ( T _ { k } ^ { \text { out } } ) \left(p_{k, t}\right.\right. \\
& \left.\left.+p_{k, t}^{\mathrm{dn}}-p_{k, t}^{\mathrm{up}}\right)+D_{k, t}\right)
\end{aligned}
$$

which is solved for discrete time following [10] as

$$
\begin{aligned}
\boldsymbol{\Phi}(\Delta t) & =e^{\frac{-\Delta t}{R_{k} C_{k}}} \\
\boldsymbol{\Gamma}(\Delta t) & =\left[\begin{array}{c}
1-e^{\frac{-\Delta t}{R_{k} C_{k}}} \\
R_{k}-R_{k} e^{\frac{-\Delta t}{R_{k} C_{k}}}
\end{array}\right]^{T}
\end{aligned}
$$


Thus, the temperature balance discrete equation (2) models heat dynamics through the time considering the indoor temperature at the previous time step, the outdoor temperature, the HP consumption and other demand emitting heat in the house. The constraints (3)-(5) bound hourly quantity bids to day-ahead market and quarterly quantity bids to the aFRR market. In addition, constraints (4) and (5) ensure that the model offers either up- or down-regulation bid for every time step. Constraints (6) limits the rate of HP consumption between any two successive time steps. The temperature level is bounded by its minimum and maximum levels (7). The equations (8)-(10) derives the aggregated bids to day-ahead and aFRR markets. The optimal bidding model derived in (1)-(11) is refereed as 'benchmark' model in our simulations.

\section{Case Study}

\subsection{Input Data}

\subsubsection{Market data acquisition}

The market data used for the analysis is freely available. The time series of day-ahead market prices $\left(\lambda_{t}\right)$, with hourly resolution, is downloaded from the ENTSO-E Transparency platform [11]. The real-time aFRR market prices $\left(\lambda_{t}^{\text {up }}\right.$ and $\lambda_{t}^{\mathrm{dn}}$ ) with 15 minutes resolution are downloaded from the TenneT's website [12]. The time series are aligned and the hourly day-ahead prices are re-sampled to 15 minutes values. The simulations are based on an example price data from January 2, 2020. Fig. 2 plots the example price data used in this paper.

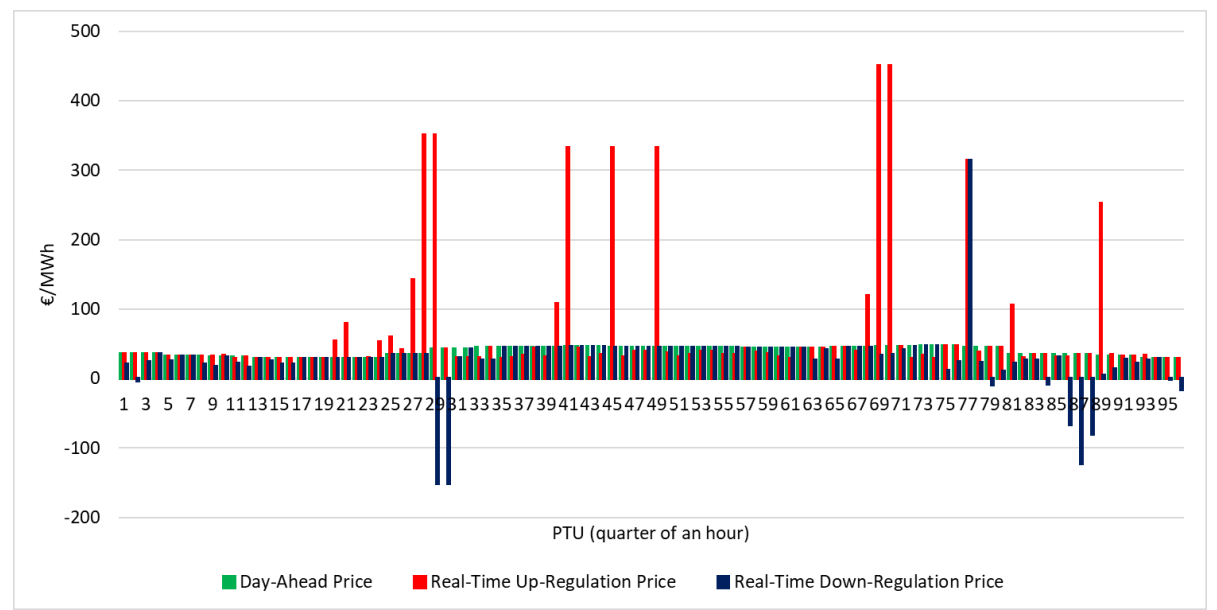

Figure 2: Day-ahead and real-time up/down-regulation prices at the Dutch energy market (2nd Jan. 2020), PTU: Per Time Unit. 


\subsubsection{General parameters}

The house parameters, $R$ and $C$, are estimated to represent three typical sizes of houses. The procedure is further described in section 7. The instantaneous coefficient of performance (COP) of a HP is defined as the ratio of the thermal power delivered to a thermal zone by the HP to the electrical power consumed. In general, the performance of a HP is primarily a function of the outdoor temperature [13]. In this paper, the COP dependence on the outside temperature $\left(f_{k}^{\text {cop }}\left(T_{k}^{\text {out }}\right)\right)$ was acquired from an actual brine/water HP found in the dwellings of FLEXCoop pilot users in the Netherlands. In particular, the COP dependence on outside temperature as well as the maximum power consumption $\left(\bar{P}_{k}\right)$ used refers to a Stiebel-Eltron WPF $07 \mathrm{~S}$ HP and the parameters were obtained from the technical data sheets of this specific brand and model [14]. More specifically, the COP values for partial load range under moderate climate conditions for standardised temperature values (for the temperature range -7 to $12{ }^{\circ} \mathrm{C}$ ) were used to obtain the following second order polynomial fit in (15).

$$
f_{k}^{\text {cop }}\left(T_{k}^{\text {out }}\right)=0.0021\left(T_{k}^{\text {out }}\right)^{2}+0.0563 T_{k}^{\text {out }}+5.11
$$

The outdoor temperature used $\left(T_{k, t}^{\text {out }}\right)$ was an indicative winter day of 2020 and was obtained through the Dark Sky API [15]. Considering that this API returns values with a granularity of an hour, a spline interpolation was performed to acquire data with 15 minutes resolution.

\subsection{Simulations results}

The optimization model is implemented in the $<$ Coliop $\mid$ Coin $>$ Mathematical Programming Language (CMPL) [16] to generate and solve the optimization problem, since various MILP problem solvers can be used, such as the freely available Cbc [17] or the commercial CPLEX [18]. The price data was extracted from the Dutch TSO, TenneT for the winter 2019/2020 period. It is assumed that the aggregator gets $20 \%$ of the market prices as refund, i.e., $c_{t}=1.2 \cdot \lambda_{t}$, $c_{t}^{u p}=0.8 \cdot \lambda_{t}^{u p}$ and $c_{t}^{d n}=1.2 \cdot \lambda_{t}^{d n}$.

\subsubsection{Illustrative small-scale study}

First simulation results with the 'benchmark' optimization model, stated in (1)-(11) (64 sites), show that the maximum capacity of HP are bought in the day-ahead market enabling the opportunity to offer a maximum amount of up-regulation power to the real time market, i.e., while reducing heating at customers' sites (cf. Fig. 3). We see from the Fig. 3 that, this behaviour is consistent for every planning period. Further experiments also (based on different price profiles) show that the down-regulation power offer is always zero. The reason causing this behaviour is the price-driven optimization benchmark model, which enables the aggregator to earn money twice: (1) when (s)he buys more energy than required at the day-ahead market and (2) sells parts of it in the real-time market offering up-regulation. The situation changes slightly 


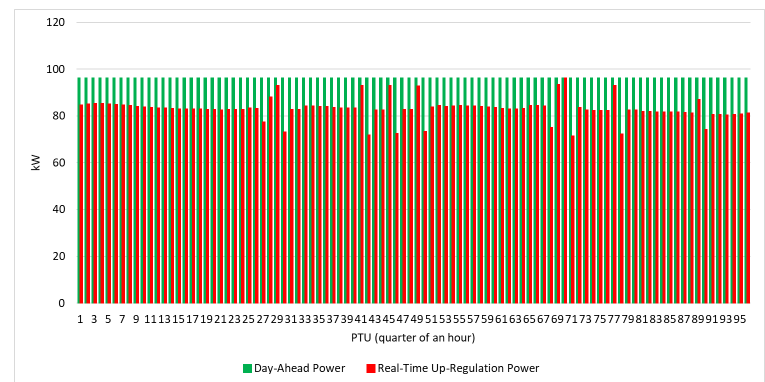

Figure 3: Offered bid volumes in day-ahead and balancing markets for an example winter day: the benchmark model.

(cf. Figure 4) when the refund factors are reduced for the day-ahead market and up-regulation (e.g., $10 \%$ ) and increased for down-regulation (e.g., $50 \%$ ).

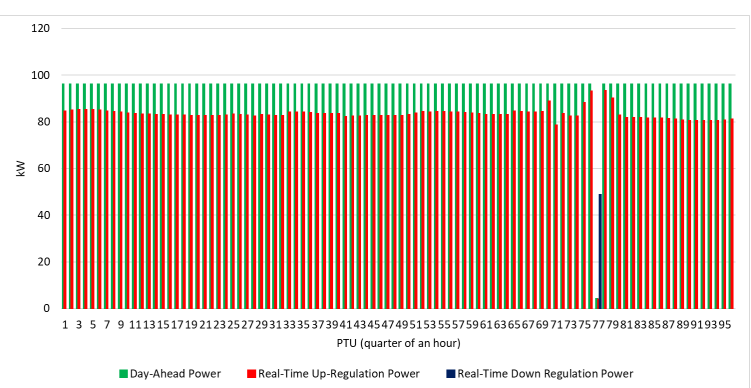

Figure 4: Offered bid volumes in day-ahead and balancing markets (with changed refund distribution): the benchmark model.

Optimization of the aggregator's bargain with the presented model implicitly assumes that all computed regulation offers to the real-time market are ideally activated, i.e., maximum comfort with minimal deviation from the cosy reference temperature $\left(21.5^{\circ} \mathrm{C}\right)$ is only guaranteed in this case. However, in practice only some of the bids (or some fraction of a bid volume) are activated and sometimes not during the whole PTU. Then, in the worst-case scenario (when none of the offers to the balancing market is activated), the indoor temperatures will increase significantly as illustrated in Fig. 5. This means, that in this scenario the aggregator will have excess energy which needs to be stored somehow either as electrical energy in a battery or as thermal energy in a heat tank. Another approach to deal with this problem is the extension of the 'benchmark' optimization model with additional constraints (16) and (17). The constraints (16) and (17) ensure the "baseline" temperatures $B_{k, t}$ remain within their lower and upper bounds assuming none of the balancing market bids are activated. The 'benchmark' MILP set out in (1)-(11) with additional constraints (16) and 


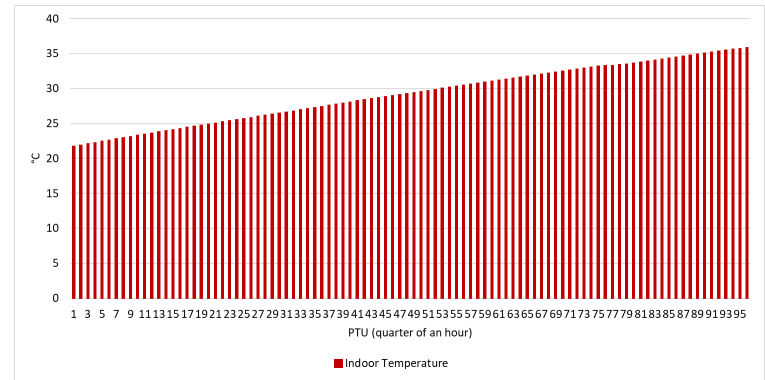

Figure 5: Indoor temperature in the worst-case scenario: the benchmark model.

(17) is referred as 'modified' model

$$
\begin{aligned}
& B_{k, t}=\boldsymbol{\Phi}_{k}(\Delta t) B_{k, t-1}+\boldsymbol{\Gamma}_{k}(\Delta t)\left[\begin{array}{c}
T_{k}^{\text {out }} \\
f_{k, t}^{\text {cop }}\left(T_{k}^{\text {out }}\right)\left(p_{k, t}+D_{k, t}\right)
\end{array}\right] \\
& \underline{T}_{k, t} \leq B_{k, t} \leq \bar{T}_{k, t}
\end{aligned}
$$

The simulation results, using the modified optimization model, show significant change in balancing bid offers at the real-time market (see Fig. 6): upand down-regulation offers are intermixed such that, even when none of the balancing bid offers is activated, the bought energy in the day-ahead market guarantees a comfortable temperature in the houses.

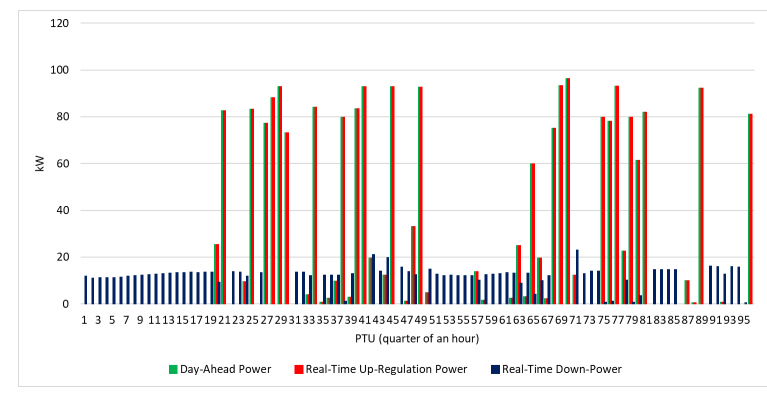

Figure 6: Offered bid volumes in day-ahead and balancing markets: the modified model.

\subsubsection{Numerical large-scale study}

Due to the fact that only bids of at least $1 \mathrm{MW}$ can be offered at the aFRR Dutch market, we run both the 'benchmark'and the 'modified' optimization models also for 1024 sites, resulting in aggregated regulation bid volume greater than the necessary $1 \mathrm{MW}$. The offered bid volumes for the large-scale study is set out in Fig. 7.

The required computation time using CPLEX is 4-5 minutes for optimal solutions with tolerance gap of $1^{-3}$. The computation time increases significantly 


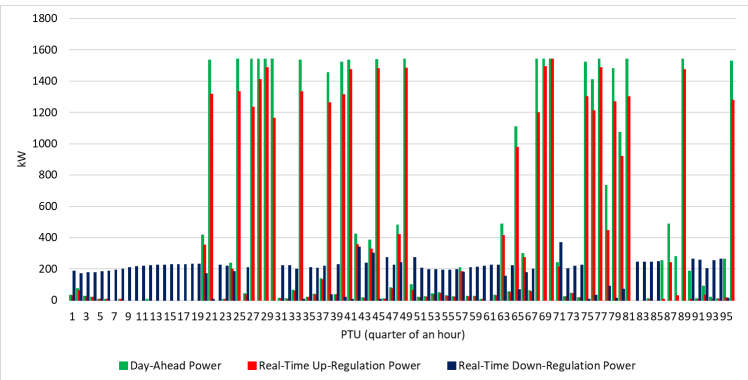

Figure 7: Offered bid volumes in day-ahead and balancing markets for 1024 sites: the modified model.

$(>1 \mathrm{~h})$ while simulating the 'modified' optimization model of the same size (1024 sites). The according problems' sizes, i.e., the total number of variables, the number of Boolean variables, the number of constraints, and the required computation times of both models and both number of sites are summarized in Table 1.

Table 1: Models' statistics together with computation times.

\begin{tabular}{c|c|c|c|c}
\hline \multicolumn{5}{c}{ 'benchmark' model } \\
\hline Sites & $\begin{array}{c}\text { Number of } \\
\text { variables }\end{array}$ & $\begin{array}{c}\text { Number of Boolean } \\
\text { variables }\end{array}$ & $\begin{array}{c}\text { Number of } \\
\text { Constraints }\end{array}$ & $\begin{array}{c}\text { Computation } \\
\text { time [sec.] }\end{array}$ \\
\hline 64 & 37218 & 6144 & 73954 & 3.39 \\
1024 & 591138 & 98304 & 1178914 & 283.25 \\
\hline \multicolumn{5}{c}{ 'modified' model } \\
\hline Sites & Number of & Number of Boolean & Number of & Computation \\
& variables & variables & Constraints & time [sec.] \\
\hline 64 & 43426 & 6144 & 92450 & 14.88 \\
1024 & 690466 & 98304 & 14749850 & 1534.44 \\
\hline
\end{tabular}

Nearly optimal solutions are computed with CPLEX in parallel mode (up to two threads) while setting the mixed integer optimality gap tolerances to 0.01 .

\section{Conclusion}

This paper proposes price-driven MILP formulations for deriving optimal coordinated bidding in day-ahead and balancing aFRR markets for a profit-maximizing HP aggregator. The prices in these markets are obtained from Dutch TSO, TenneT. The developed models (the original 'benchmark' and extended 'modified' ) are tested on an illustrated small scale and a numerical large scale studies. Simulation results, using benchmark optimization model, lead to dominant bidding behaviour: the model bids to day-ahead market with the maximum capacity, then offers up-regulation bids. This bidding behaviour might result 
a lack of respect for the comfort of involved houses, taking into consideration that real-time market is more risky (bid offers in balancing market might not be activated, or might be partly activated). The benchmark optimization model has been extended to tackle this issue. The modified MILP model leads to more reliable results, which ensures comfortable temperature in the involved sites. Simulations results from the numerical study (involving 1024 sites) proof the applicability of the model on a large scale. The current paper can be extended in several ways: 1) by adopting an accurate forecasting model for predicting prices in two-settlement markets, 2) by developing the stochastic MILP for better accounting the uncertainties related to the day-ahead and balancing market prices, 3 ) by modelling the risk to better cope with electricity price volatility 4 ) by including the intra-day market modelling.

\section{ACKNOWLEDGEMENTS}

This work has been carried out in the context of FLEXCoop project. The FLEXCoop project is funded by the European Union's Horizon 2020 research and innovation programme - No 773909 grant agreement (http://www.flexcoop.eu/).

\section{Appendix}

The parameters $R$ and $C$ are calculated according to the building material composition defined in [19] (with adjusted insulation thickness to reflect a typical building - presumably represented by the building codes in Northern European countries from 1995). Briefly, the $R$ calculations follow

$$
R=\frac{1}{U \frac{k W}{m^{2} K}}
$$

where $U$ is the $\mathrm{U}$-value of the building envelope (the sum of the U-values in the walls, windows, doors and roof). $C$ is calculated based on the sum of heat capacities in the building envelope (inside of the insulation) and the room (furnished). An estimate for furnished rooms is $20 \frac{\mathrm{KJ}}{\mathrm{K} \cdot \mathrm{m}^{2}}$ in [20].

Human activity in the buildings is modelled as the disturbance, $D(t)$. For this purpose, a data set with various sensor time series data (e.g. movement, lighting, temperature) from 25 houses, [21], has been analysed. The data shows various events with an activity tag on e.g. "Sleeping" or "Watching TV". Each activity and representative electricity consumption from electric devices (e.g computer and TV) are assigned with a corresponding heat contribution, $Q_{\text {activity }}$, found in [22]. Assumptions have been made for simple heat contribution calculations for activities like opening a door and taking a shower. These reveals hourly patterns of heat contribution for each house. 


\section{References}

[1] "Energy roadmap 2050," European Commission, Tech. Rep., 2012.

[2] Y. Vardanyan and H. Madsen, "Stochastic bilevel program for optimal coordinated energy trading of an ev aggregator," Energies, vol. 12, no. 20, pp. 1-18, Oct. 2019.

[3] K. Bruninx, H. Pandžic, H. Le Cadre, and E. Delarue, "On controllability of demand response resources \& aggregators' bidding strategies," in Power Systems Computation Conference, June 2018.

[4] T. S. Pedersen, P. Andersen, K. M. Nielsen, H. Stærmose, and P. Pedersen, "Using heat pump energy storages in the power grid," in IEEE International Conference on Control Applications, Sep. 2011.

[5] B. Biegel, P. Andersen, T. Pedersen, K. Nielsen, J. Stoustrup, and L. Stoustrup, "Electricity market optimization of heat pump portfolio," in IEEE International Conference on Control Applications, Aug. 2013.

[6] J. Posma, I. Lampropoulos, W. Schram, and W. Sark, "Provision of ancillary services from an aggregated portfolio of residential heat pumps on the dutch frequency containment reserve market," Applied Sciences, vol. 9, no. 3, Feb. 2019.

[7] "Trading on epex spot," Available at http://static.epexspot.com/ document/38579/Epex\_TradingBrochure\_180129\_Web.pdf, 2018.

[8] "Product information automatic frequency restoration reserve," Available at https://www.tennet.eu/fileadmin/user \_upload/SO \_NL/Product $\backslash$ information $\backslash$ aFRR $\backslash 2018-12-18$.pdf, 2018.

[9] "Implementation guide," Available at https://www.tennet.eu/fileadmin/ user \_upload/SO \_NL/Uitvoeringsregels \_4.5\_\_UK.pdf.

[10] H. Madsen and J. Holst, "Estimation of continuous-time models for the heat dynamics of a building," Energy and Buildings, vol. 22, no. 1, pp. 67-79, 1995.

[11] ENTSO-E. Day-ahead market prices. [Online]. Available: https: //transparency.entsoe.eu/transmission-domain/r2/dayAheadPrices/show

[12] Tennet. Balancing market prices. [Online]. Available: https://www.tennet.org/english/operational_management/ System_data_relating_implementation/system_balance_information/ balancedelta2017.aspx

[13] "TRNSYS 17, a TRaNsient SYstem Simulation program, Volume 4 Mathematical Reference," http://web.mit.edu/parmstr/Public/TRNSYS/04MathematicalReference.pdf, 2009. 
[14] STIEBEL-ELTRON. [Online]. Available: https://www. stiebel-eltron.co.uk/en/products-solutions/renewables/heat_pump/ brine_water_heatpumps/wpf_05_07_10_13_s/wpf_07_s.html

[15] DarkSky. [Online]. Available: https://darksky.net/dev

[16] M. Steglich and T. Schleiff, "CMPL: Coliop Mathematical Programming Language - Version 1.12 - March 2018," 2018.

[17] J. Forrest, "CBC User Guide," https://www.coinor.org/Cbc/cbcuserguide.html.

[18] IBM, "ILOG CPLEX Optimization Studio - Survey," https://www.ibm.com/products/ilog-cplex-optimization-studio, Jan. 2019 .

[19] K. Leerbeck, P. Bacher, R. G. Junker, A. Tveit, and H. Madsen, "Control of heat pumps with CO2 emission intensity forecasts," 2020.

[20] "French building energy and thermal regulation," 2005.

[21] D. Cook, A. Crandall, and B. Thomas, "Human activity recognition from continuous ambient sensor data data set," Available at https://archive.ics.uci.edu/ml/datasets/Human+Activity+Recognition+ from+Continuous+Ambient+Sensor+Data, 2019, [Online; accessed 9-Mar-2020].

[22] "Calories burned in 30 minutes for people of three different weights," Available at https://www.health.harvard.edu/diet-and-weight-loss/ calories-burned-in-30-minutes-of-leisure-and-routine-activities, 2014, [Online; accessed 09-Mar-2020]. 